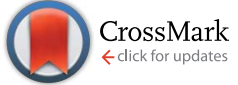

Cite this: RSC Adv., 2014, 4, 36401
Received 19th June 2014 Accepted 6th August 2014 DOI: $10.1039 / c 4 r a 05998 k$ www.rsc.org/advances

\section{One-pot sonochemical synthesis of reduced graphene oxide uniformly decorated with ultrafine silver nanoparticles for non-enzymatic detection of $\mathrm{H}_{2} \mathrm{O}_{2}$ and optical detection of mercury ions}

\begin{abstract}
A. Moradi Golsheikh, ${ }^{\text {ab }}$ N. M. Huang, ${ }^{\text {*a }}$ H. N. Lim ${ }^{c}$ and Rozalina Zakaria ${ }^{d}$
Reduced graphene oxide ( $r G O$ ) uniformly decorated with silver nanoparticles (AgNPs) was synthesized through the simple ultrasonic irradiation of an aqueous solution containing a silver ammonia complex $\left(\mathrm{Ag}\left(\mathrm{NH}_{3}\right)_{2} \mathrm{OH}\right)$ and graphene oxide (GO). The results of $\mathrm{X}$-ray diffraction, Fourier-transform infrared transmission spectroscopy, X-ray photoelectron spectroscopy and Raman spectroscopy confirmed the simultaneous formation of cubic-phase AgNPs and the reduction of GO through an ultrasonication process. The size of the nanoparticles could be tuned by adjusting the volume ratio of the precursors and the ultrasonic irradiation time. Transmission electron microscopy images showed a uniform distribution of ultrafine spherical AgNPs with a narrow size distribution on the rGO sheets, which could only be achieved using the silver ammonia complex, rather than silver nitrate, as the precursor. The average particle size of the silver with the narrowest size distribution was $4.57 \mathrm{~nm}$. The prepared AgNPsrGO modified glassy carbon electrode exhibited notable electrocatalytic activity toward the nonenzymatic detection of $\mathrm{H}_{2} \mathrm{O}_{2}$ with a wide linear range of $0.1-70 \mathrm{mM}\left(R^{2}=0.9984\right)$ and a detection limit of $4.3 \mu \mathrm{M}$. Furthermore, the prepared AgNPs-rGO composite was employed for the spectral detection of $\mathrm{Hg}^{2+}$ ions and showed a detection limit of $20 \mathrm{nM}$.
\end{abstract}

\section{Introduction}

Graphene, a one-atom-thick sheet of $\mathrm{sp}^{2}$-bonded carbon atoms, has unique electronic, mechanical and thermal properties..$^{1-3}$ Thus, it has potential applications in many advanced technologies, including nanoelectronics, sensors, capacitors and composites. $^{4-7}$ At present, graphene nanosheets are prepared using a variety of techniques, including the micromechanical exfoliation of graphite, chemical vapour deposition, electrochemical reduction of graphene oxide (GO), epitaxial growth and thermal or chemical reduction of graphite oxide., ${ }^{\mathbf{1 , - 1 2}}$ Recently, a sonochemical method was reported as a facile, fast and cost-effective route for the reduction of GO to form graphene nanosheets. ${ }^{13}$

\footnotetext{
${ }^{a}$ Low Dimensional Materials Research Centre (LDMRC), Physics Department, Faculty of Science, University of Malaya, 50603 Kuala Lumpur, Malaysia. E-mail: huangnayming@um.edu.my; amir_moradi_g@ymail.com; Fax:+60 379674146; Tel: +60122091008

${ }^{b}$ Nanotechnology Laboratory, Esfarayen University of Technology, Esfarayen 9661998195, North Khorasan, Iran

${ }^{c}$ Department of Chemistry, Faculty of Science, University Putra Malaysia, 43400 UPM Serdang, Selangor Darul Ehsan, Malaysia

${ }^{d}$ Photonics Research Centre, Physics Department, Faculty of Science, University of Malaya, 50603 Kuala Lumpur, Malaysia
}

Graphene's favourable characteristics, including its high electrical conductivity, large surface-to-volume ratio and excellent chemical tolerance, render it a distinguishable matrix for composites. In view of this, metal-nanoparticle-decorated graphene composites have been the focus of research in recent years because of their multifunctional abilities. Among these, silver-nanoparticle (AgNP)-decorated graphene composites are consistently some of the most frequently researched composites because they are effective in various applications, including surface-enhanced Raman scattering (SERS) substrates, glucose sensors and hydrogen peroxide sensors. ${ }^{\mathbf{1 4 - 1 6}}$ These AgNPdecorated graphene composites are prepared using different strategies: (1) the in situ reduction of silver ions on the surface of GO and simultaneous reduction of GO to graphene, ${ }^{16,17}$ (2) in situ reduction of silver ions on the surface of pre-formed reduced $\mathrm{GO}^{18,19}$ and (3) decoration of pre-formed reduced GO with pre-synthesized AgNPs. ${ }^{\mathbf{1 5 , 2 0}}$ The latter two strategies involve multiple steps, which make the preparation process complex. In addition, AgNP-decorated graphene composites normally require chemical reducing and/or stabilizing agents (such as ethylene glycol, ${ }^{21}$ hydrazine, ${ }^{22}$ and poly(diallydimethylammonium chloride) (PDDA) ${ }^{23}$ ), some of which are toxic.

In recent years, a sonochemical method has proven to be a versatile and promising technique for the synthesis of a variety of nanostructures such as metals, ${ }^{24-26}$ metal oxides ${ }^{27,28}$ and 
metal sulphides. ${ }^{28,29}$ The chemical effects of ultrasound irradiation arise from the acoustic cavitation phenomenon. When a liquid is irradiated with ultrasound, bubbles are created, which allow the ultrasonic energy to accumulate during growth. The unstable gas-liquid interface subsequently collapses, releasing the stored energy within a very short time. These cavitational implosions generate localized hotspots with a high temperature of $5000 \mathrm{~K}$, pressure of $1000 \mathrm{bar}$ and heating and cooling rate of $10^{10} \mathrm{~K} \mathrm{~s}^{-1}$. $^{30}$ These extreme conditions are suitable for reducing GO and metal ions. Recently, a sonochemical strategy has been used for the synthesis of graphene-based inorganic nanocomposites such as metals, ${ }^{31,32}$ bimetals $^{33}$ and metal oxides. ${ }^{34-36}$ Herein, we report a fast, one-step, cost-effective and environmentally friendly synthesis of rGO uniformly decorated with ultrafine AgNPs using a sonochemical method that does not involve chemical reducing and/or stabilizing agents.

\section{Experimental}

\subsection{Materials}

Graphite flakes were purchased from Ashbury Inc. (NJ, USA). Sulphuric acid $\left(\mathrm{H}_{2} \mathrm{SO}_{4}, 98 \%\right)$, potassium permanganate $\left(\mathrm{KMnO}_{4}, 99.9 \%\right)$, hydrogen peroxide $\left(\mathrm{H}_{2} \mathrm{O}_{2}, 30 \%\right)$, hydrochloric acid $(\mathrm{HCl}, 37 \%)$ and sodium hydroxide $(\mathrm{NaOH}, 99.99 \%)$ were purchased from Merck. Silver nitrate $\left(\mathrm{AgNO}_{3}, 99.7 \%\right)$ was purchased from Systerm, Malaysia. An ammonia solution $\left(\mathrm{NH}_{3}\right.$, $25 \%$ ) was obtained from Sigma-Aldrich. Distilled water was used throughout the sample preparation.

\subsection{Preparation of AgNPs-rGO composite}

GO was prepared using a simplified Hummers' method. ${ }^{37}$ A silver-ammonia $\left[\mathrm{Ag}\left(\mathrm{NH}_{3}\right)_{2} \mathrm{OH}\right]$ solution was prepared by adding ammonia $(1 \mathrm{w} / \mathrm{v} \%)$ to a silver nitrate solution $(50 \mathrm{mM})$ until the complete absence of precipitates was observed. The concentration of the obtained $\mathrm{Ag}\left(\mathrm{NH}_{3}\right)_{2} \mathrm{OH}$ was approximately $40 \mathrm{mM}$. The freshly prepared $\mathrm{Ag}\left(\mathrm{NH}_{3}\right)_{2} \mathrm{OH}$ solution was mixed with an aqueous solution of GO $\left(1.0 \mathrm{mg} \mathrm{mL}{ }^{-1}\right)$ at GO-to-Ag $\left(\mathrm{NH}_{3}\right)_{2} \mathrm{OH}$ volume ratios of 8,4 and 2 (the samples were labelled AgNPsrGO-1, AgNPs-rGO-2 and AgNPs-rGO-3, respectively) and stirred for $5 \mathrm{~min}$ to ensure homogeneity. The resulting solutions were exposed to acoustic cavitation by using an ultrasonic horn (Misonix Sonicator S-4000, USA, $20 \mathrm{kHz}$ ) immersed directly into the solutions at a $60 \%$ amplitude for $5 \mathrm{~min}$, with a $3 \mathrm{~s}$ pulse and 5 s relaxation cycle. The products were centrifuged and washed with distilled water three times and were finally redispersed in water. To investigate the effect of the ultrasonic irradiation time, AgNPs-rGO-4 and AgNPs-rGO-5 were prepared by using ultrasonic irradiation times of 15 and $30 \mathrm{~min}$, respectively, for the same solution as AgNPs-rGO-2. The ultrasonic reaction was conducted without cooling. Thus, temperatures of approximately 65,75 and $80{ }^{\circ} \mathrm{C}$ were achieved at the end of the 5, 15 and $30 \mathrm{~min}$ reaction times, respectively. For comparison, AgNPsrGO-6 was prepared under the same conditions as AgNPs-rGO-2 using an $\mathrm{AgNO}_{3}$ solution $(0.04 \mathrm{M})$ instead of the $\mathrm{Ag}\left(\mathrm{NH}_{3}\right)_{2} \mathrm{OH}$ solution $(0.04 \mathrm{M})$.

\subsection{Preparation of modified electrode}

A glassy carbon electrode (GCE) was polished using 1.0- and 0.3 $\mu \mathrm{m}$ alumina powders and then sonicated in ethanol and distilled water for $1 \mathrm{~min}$ each. Finally, the electrode was dried in a stream of nitrogen, and $5 \mu \mathrm{L}$ of a suspension of the AgNPs/rGO composite was dropped onto the pre-cleaned GCE and allowed to dry in air at room temperature. An electrochemical sensing application of AgNPs-rGO was conducted on a potentiostat/ galvanostat (Versastat 3 Applied Research Princeton, USA) using a three-electrode system, with a modified GCE (with an active area of $0.07 \mathrm{~cm}^{2}$ ) as the working electrode, a platinum wire as the counter electrode and a saturated calomel electrode (SCE) as the reference electrode.

\subsection{Spectral detection of $\mathbf{H g}^{2+}$ ions}

The spectral detection of $\mathrm{Hg}^{2+}$ ions using the AgNPs/rGO composite was performed using a UV-visible spectrometer (Thermo Scientific Evolution). The absorption spectra of the AgNPs/rGO composite were recorded after adding different concentrations of $\mathrm{Hg}^{2+}$ ions from 0.1 to $100 \mu \mathrm{M}$. To monitor the absorption spectra, a freshly prepared solution of $\mathrm{Hg}^{2+}$ ions was added to $4 \mathrm{~mL}$ of the AgNPs/rGO composite, shaken well, and allowed a constant resting time $(8 \mathrm{~min})$. For selective detection, $100 \mu \mathrm{M}$ of the analyte $\left(\mathrm{Hg}^{2+}, \mathrm{Fe}^{2+}, \mathrm{K}^{+}, \mathrm{Mn}^{2+}, \mathrm{Pb}^{2+}, \mathrm{Zn}^{2+}, \mathrm{Cd}^{2+}\right.$, $\mathrm{Cu}^{2+}$ and $\mathrm{Ni}^{2+}$ ions) was added to the AgNPs/rGO composite, and the changes in the absorption spectra were recorded. The limits of detection (LODs) for both hydrogen peroxide and mercury ions were calculated using the following equation:

$$
\mathrm{LOD}=3 S / b
$$

where $S$ is the standard deviation of the blank, and $b$ is the slope of the calibrated curve.

\subsection{Characterization}

The crystal phase, morphology and microstructure of the samples were characterized using the X-ray powder diffraction (XRD; Philips X'pert system using $\mathrm{Cu} \mathrm{K}_{\alpha}$ radiation), a UV-visible spectrometer (Thermo Scientific Evolution), a high-resolution transmission electron microscope (HRTEM, JEOL JEM-2100F), a Fourier-transform infrared spectrometer (FTIR; Perkin Elmer System 2000 series spectrophotometer, USA), X-ray photoelectron spectroscopy (XPS) (measurements were taken using synchrotron light at beamline no. 3.2 of the Siam Photon Laboratory in the Synchrotron Light Research Institute, Thailand) and a Raman spectrometer (Renishaw inVia Raman microscope using laser excitation at $\lambda=514 \mathrm{~nm}$ ).

\section{Results and discussion}

Fig. 1 shows the XRD patterns of pristine GO (a), a sample holder (b) and AgNPs-rGO prepared at different reaction times (c-e) (5, 15 and $30 \mathrm{~min}$, respectively). The pristine GO has a sharp peak at $10.8^{\circ}$, which is assigned to the (002) inter-planar spacing of $0.82 \mathrm{~nm} .{ }^{38}$ Meanwhile, the XRD pattern of the sample holder has a broad peak at about $2 \theta=13^{\circ}$, which is observed in 
the XRD patterns of all the samples. As shown in Fig. 1(c)-(e), the XRD patterns of AgNPs-rGO composites exhibit broad peaks at $38.1^{\circ}, 44.3^{\circ}, 64.2^{\circ}$ and $77.6^{\circ}$, which can be indexed to the (111), (200), (220) and (311) planes of the cubic Ag crystal, respectively (PDF card no: 00-004-0783). The calculated lattice spaces of the (111), (200), (220) and (311) planes are 2.36, 2.05, 1.44 and $1.23 \AA$, respectively. The average crystallite sizes of the AgNPs-rGO composites prepared at 5, 15 and $30 \mathrm{~min}$, calculated using the size strain plot method, ${ }^{39}$ are 5.6, 6.6 and $8.3 \mathrm{~nm}$, respectively. As the ultrasonic irradiation time increases, the intensity of the peaks and the average crystallite size increase, indicating the formation of AgNPs with a larger average size. Meanwhile, the (002) peak of GO disappeared after the sonication process. This is attributed to the growth of AgNPs on the

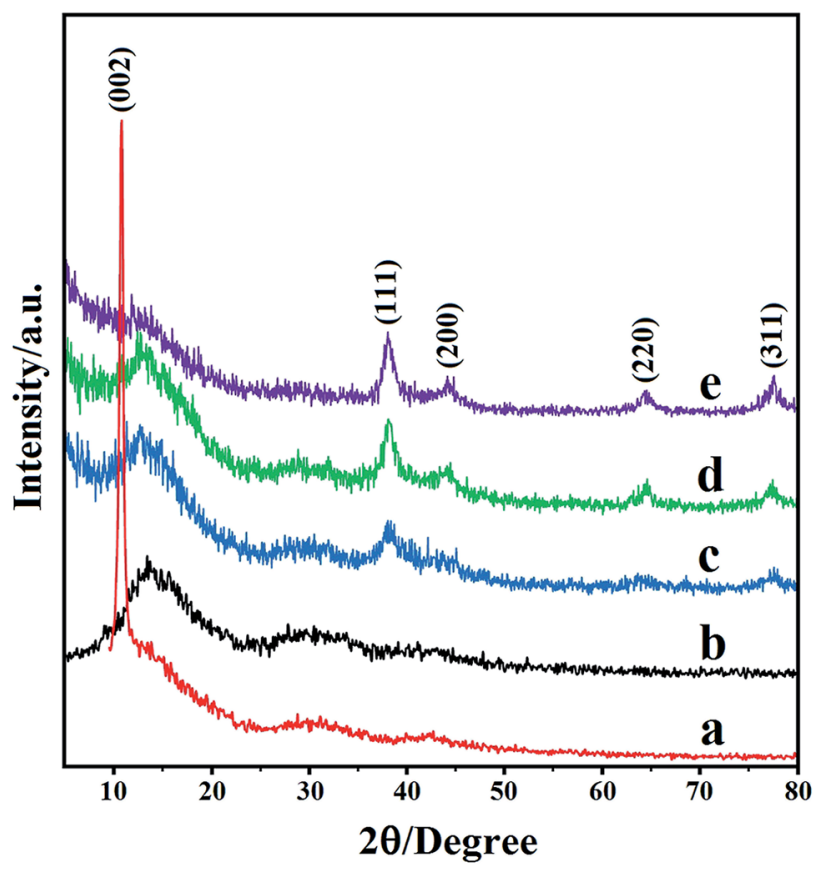

Fig. 1 XRD patterns of pristine GO (a), sample holder (b) and AgNPsrGO prepared at different ultrasonic irradiation times: 5 min (c), 15 min (d) and $30 \mathrm{~min}(\mathrm{e})$. surface of the graphene sheets, which prevented the restacking of the graphene sheets. ${ }^{38}$

Fig. 2A shows the UV-Vis absorption spectra of GO and AgNPs-rGO. In the UV-Vis spectrum of GO, two characteristic peaks can be observed at 229 and $304 \mathrm{~nm}$, which are attributed respectively to $\pi-\pi^{*}$ transitions of aromatic $\mathrm{C}=\mathrm{C}$ bonds and $\mathrm{n}-\pi^{*}$ transitions of $\mathrm{C}=\mathrm{O}$ bonds. ${ }^{40}$ After ultrasonic irradiation of the $\mathrm{Ag}\left(\mathrm{NH}_{3}\right)_{2} \mathrm{OH}$ and $\mathrm{GO}$ solution, those peaks disappeared, and two new peaks appeared at 251 and $396 \mathrm{~nm}$, which correspond to the reduction in GO and surface plasmon resonance (SPR) of the spherical AgNPs, respectively. ${ }^{\mathbf{4 1 , 4 2}}$ The inset of Fig. 2A shows a photograph of the solution of $\mathrm{Ag}\left(\mathrm{NH}_{3}\right)_{2} \mathrm{OH}$ and GO before and after ultrasonic irradiation treatment, in which the colour changes from yellow brown to black. Fig. 2B(a)-(d) shows the effect of the ultrasonic irradiation time on the formation of the AgNPs-rGO composites. After 5 min of ultrasonic irradiation, a slight absorption band at $396 \mathrm{~nm}$ appears. Meanwhile, the peak can be clearly observed at $15 \mathrm{~min}$, indicating the presence of spherical AgNPs. A further increase in the reaction time induced a heightened peak intensity at $396 \mathrm{~nm}$ and the "red enlargement" of this peak. The enhanced peak intensity and broadness imply the increased concentration of silver, which is attributed to the increased amount and size of the AgNPs, as proven in the subsequent discussion on the morphology of the composite observed using the HRTEM.

Fig. 3 shows the FTIR spectra of pristine GO (a) and AgNPsrGO composites that were prepared at different ultrasonic irradiation times (b-d) (5, 15 and 30 min, respectively). For GO, the broad peak centred at $3227 \mathrm{~cm}^{-1}$ is attributed to the $\mathrm{O}-\mathrm{H}$ stretching vibrations, whereas the peaks at 1735, 1626, 1381 and $1225 \mathrm{~cm}^{-1}$ are assigned to the $\mathrm{C}=\mathrm{O}$ stretching, $\mathrm{sp}^{2}$-hybridized $\mathrm{C}=\mathrm{C}$ group and $\mathrm{O}-\mathrm{H}$ bending, $\mathrm{C}-\mathrm{OH}$ stretching and $\mathrm{C}-\mathrm{O}-\mathrm{C}$ stretching, respectively. ${ }^{43}$ Meanwhile, the peaks at 1169 and $1046 \mathrm{~cm}^{-1}$ can be attributed to the $\mathrm{C}-\mathrm{O}$ vibration of the epoxy or alkoxy groups. ${ }^{44}$ For the AgNPs-rGO composites, the peak at $1597 \mathrm{~cm}^{-1}$ is assigned to the $\mathrm{sp}^{2}$-hybridized $\mathrm{C}=\mathrm{C}$ group. The peak at $1169 \mathrm{~cm}^{-1}$ for GO is absent for the AgNPs-rGO composites, and the intensity of the peaks, related to the oxygen-containing groups, decreases for the AgNPs-rGO composites, indicating the reduction of GO during the ultrasonic irradiation process. In addition, Fig. 3 shows that the peak
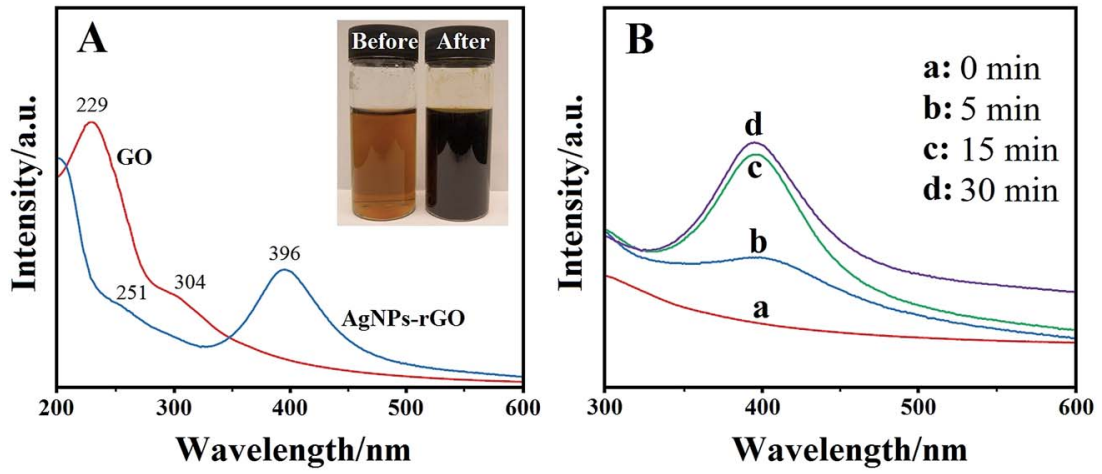

Fig. 2 (A) UV-Vis absorption spectra of GO and AgNPs-rGO (inset shows photograph of solution of $\mathrm{GO}$ and $\mathrm{Ag}\left(\mathrm{NH}_{3}\right)_{2} \mathrm{OH}$ before and after ultrasonic irradiation) and (B) time evolution of UV-Vis absorption spectra of AgNPs-rGO. 


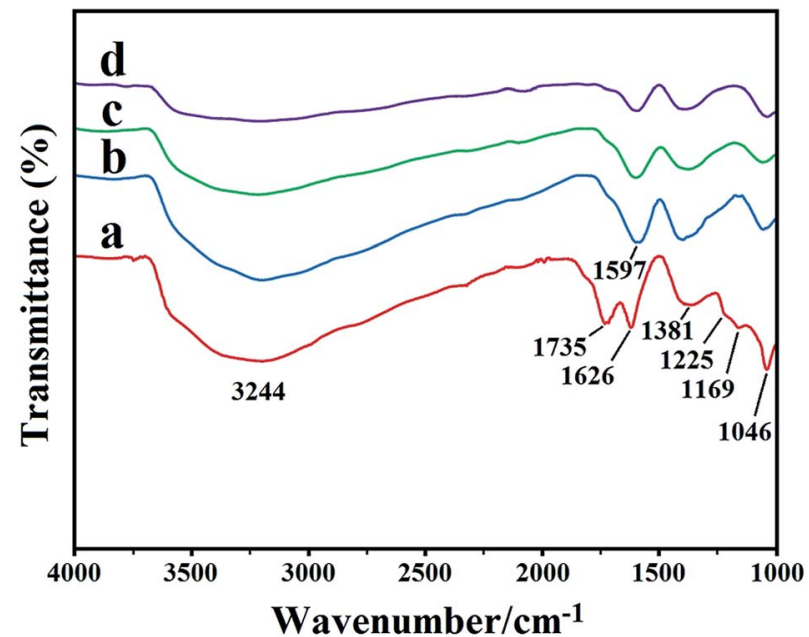

Fig. 3 FTIR spectra of pristine GO (a) and AgNPs-rGO prepared at different ultrasonic irradiation times: $5 \mathrm{~min}$ (b), $15 \mathrm{~min}$ (c) and $30 \mathrm{~min}$ (d).

intensity of the oxygen-containing groups decreases gradually with an increase in the ultrasonic irradiation time, which indicates the stepwise removal of oxygen-containing groups.

The XPS spectra further proved the reduction of GO after ultrasonic treatment. As shown in Fig. 4a, the $\mathrm{C} 1$ band of pristine GO can be fitted to four deconvulated components, centred at $284.5,286.2,287.8$ and $289 \mathrm{eV}$, which are assigned to the nonoxygenated ring $\mathrm{C}$, the $\mathrm{C}$ in $\mathrm{C}-\mathrm{O}$, the $\mathrm{C}$ in $\mathrm{C}=\mathrm{O}$ and the $\mathrm{C}$ in $\mathrm{C}(\mathrm{O}) \mathrm{O}$, respectively. ${ }^{45,46} \mathrm{In}$ comparison to the pristine GO, the $\mathrm{C} 1$ band of the AgNPs-rGO composites shows that the peak intensity of the oxygenated carbonaceous bands decreased, indicating the reduction of GO after ultrasonic treatment. In

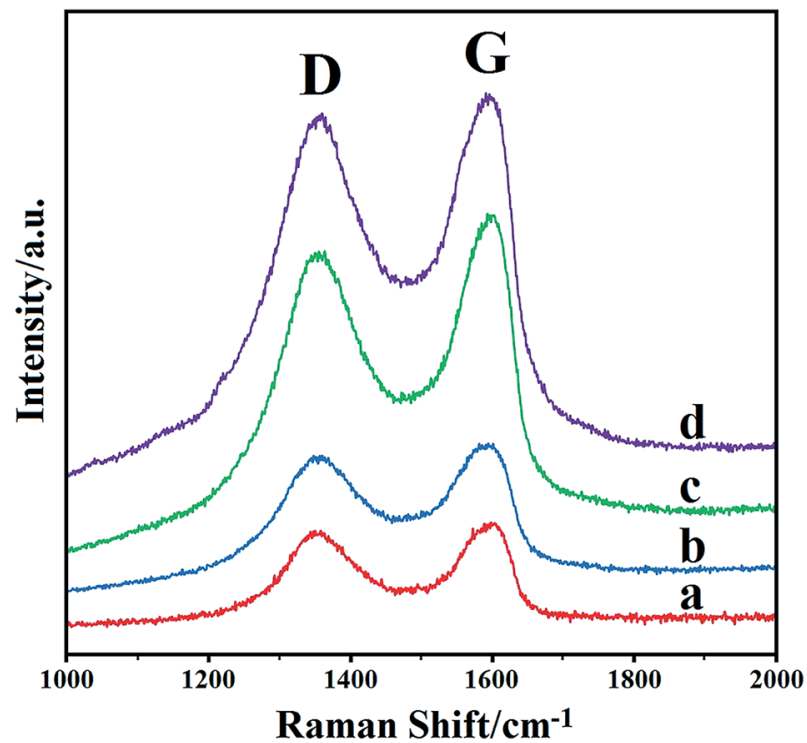

Fig. 5 Raman spectra of pristine GO (a) and AgNPs-rGO prepared at different ultrasonic irradiation times: $5 \mathrm{~min}$ (b), $15 \mathrm{~min}$ (c) and $30 \mathrm{~min}$ (d).

Table $1 \mathrm{D}$ and $G$ peak positions and intensity ratios of $/(D) / /(G)$ (obtained by Raman analysis) of GO and AgNPs-rGO composites prepared at different ultrasonic irradiation times

\begin{tabular}{lllll}
\hline & GO & $\begin{array}{l}\text { AgNPs-rGO } \\
(5 \mathrm{~min})\end{array}$ & $\begin{array}{l}\text { AgNPs-rGO } \\
(15 \mathrm{~min})\end{array}$ & $\begin{array}{l}\text { AgNPs-rGO } \\
(30 \mathrm{~min})\end{array}$ \\
\hline $\mathrm{D}$ band $\left(\mathrm{cm}^{-1}\right)$ & 1350 & 1360 & 1363 & 1360 \\
$\mathrm{G}$ band $\left(\mathrm{cm}^{-1}\right)$ & 1603 & 1594 & 1593 & 1591 \\
$I(\mathrm{D}) / I(\mathrm{G})$ & 0.91 & 0.88 & 0.87 & 0.95
\end{tabular}
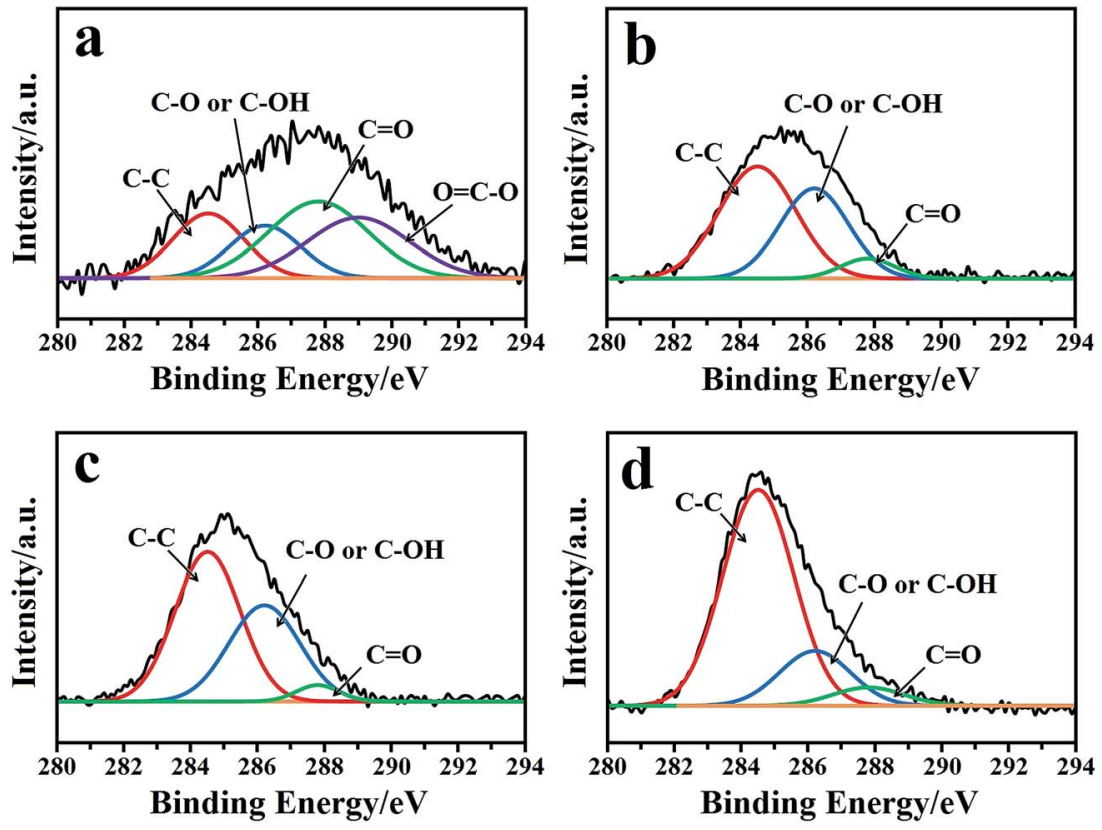

Fig. 4 XPS spectra of pristine GO (a) and AgNPs-rGO prepared at different ultrasonic irradiation times: 5 min (b), 15 min (c) and 30 min (d). 

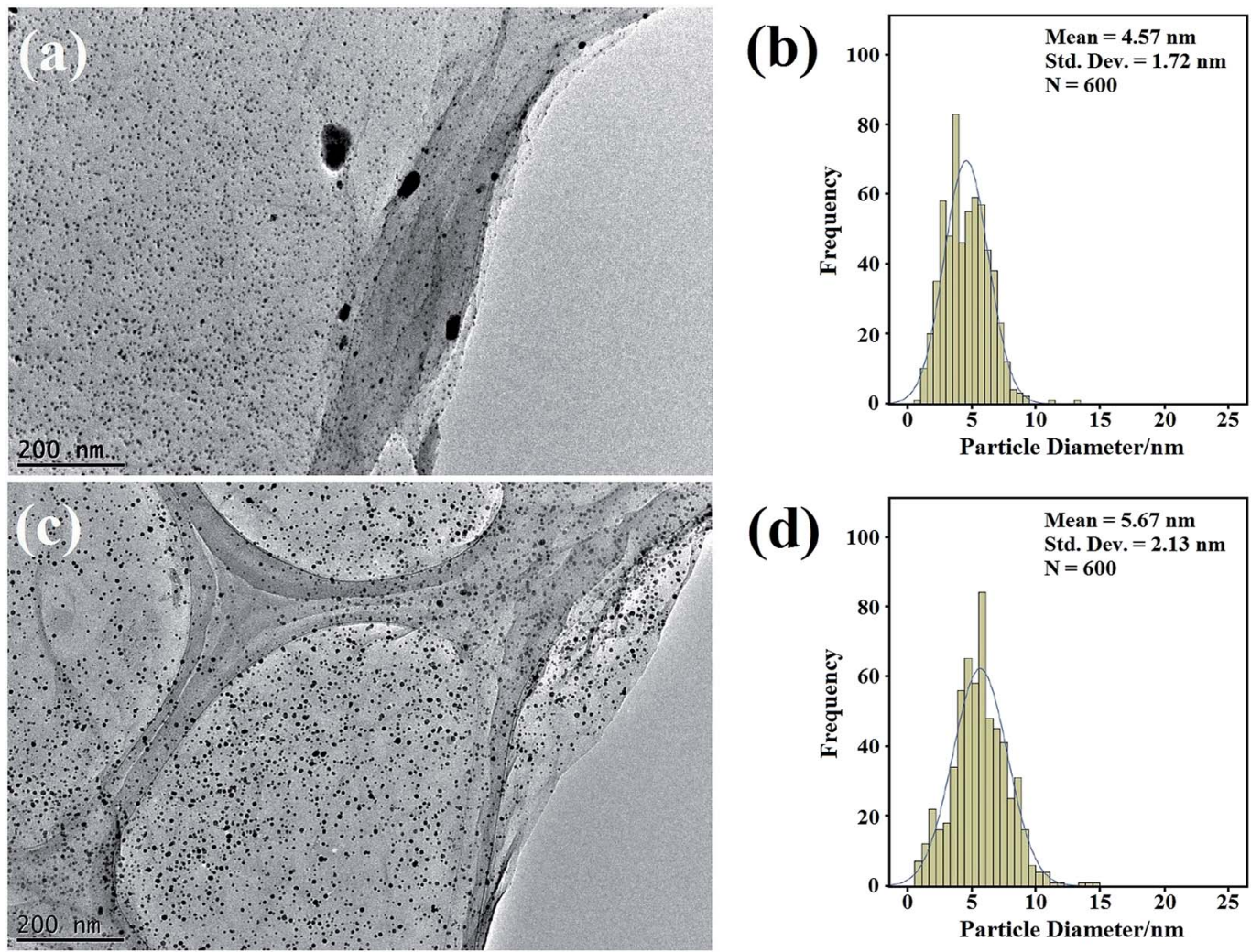

(d)
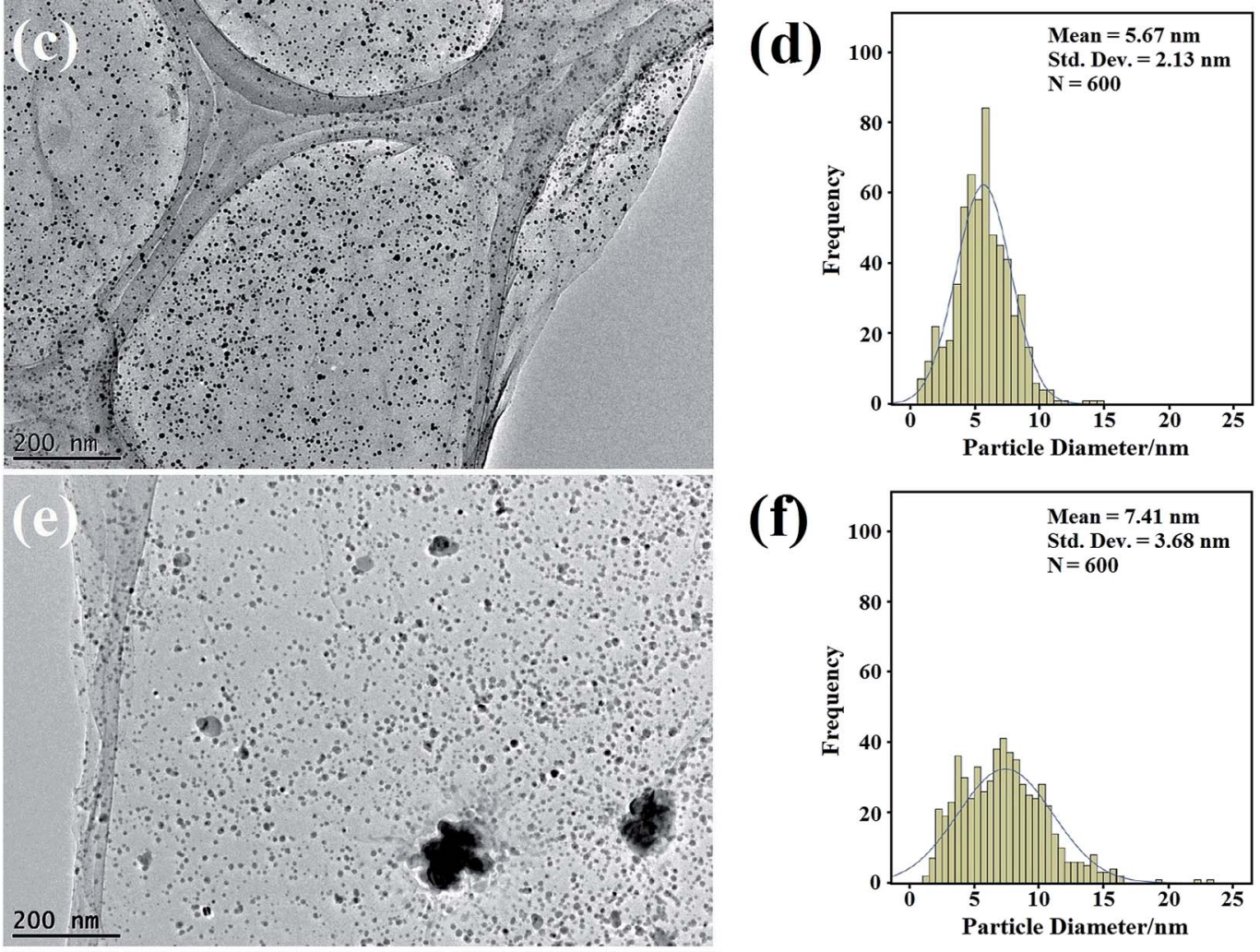

(f)
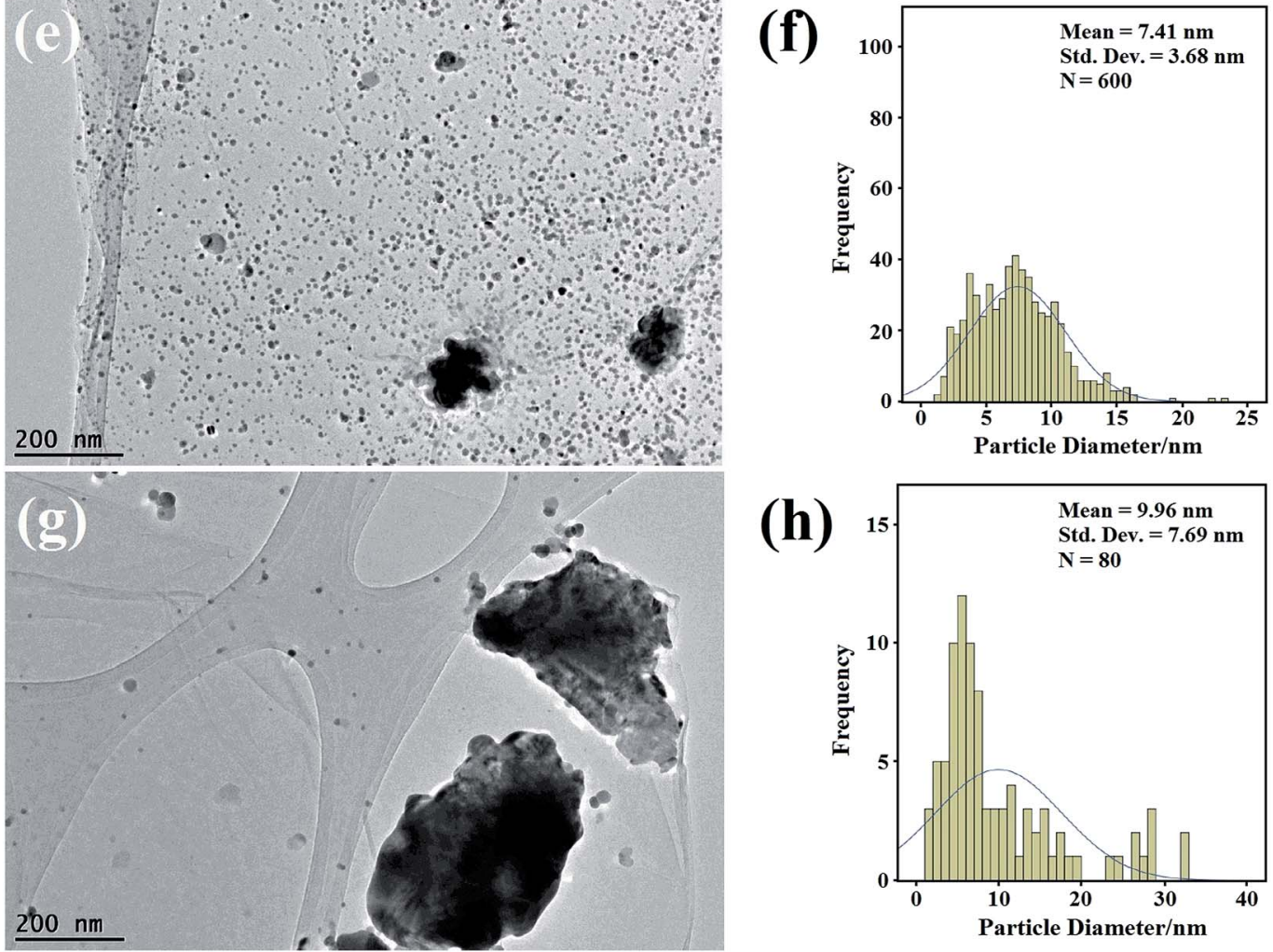

Fig. 6 TEM images and size distribution diagrams of AgNPs-rGO prepared using solutions with $\mathrm{GO}\left(1.0 \mathrm{mg} \mathrm{mL}^{-1}\right)$ to $\mathrm{Ag}\left(\mathrm{NH}_{3}\right)_{2} \mathrm{OH}(0.04 \mathrm{M})$ volume ratios of $8\left(\mathrm{a}\right.$ and b), 4 ( $\mathrm{c}$ and $\mathrm{d}$ ) and 2 (e and f), as well as solution with $\mathrm{GO}\left(1.0 \mathrm{mg} \mathrm{mL}^{-1}\right.$ ) to AgNO $3(0.04 \mathrm{M})$ volume ratio of 4 ( $\mathrm{g}$ and $\mathrm{h}$ ), with same ultrasonic irradiation time of $5 \mathrm{~min}$. 
addition, the peak intensity of the oxygenated carbonaceous bands gradually decreases with an increase in the ultrasonic irradiation time, which is consistent with the FTIR results.

Fig. 5 shows the Raman spectra for pristine GO (a) and the AgNPs-rGO composites with different ultrasonic irradiation times (b-d) (5, 15 and $30 \mathrm{~min}$, respectively). The Raman spectrum of GO shows two peaks at 1350 and $1603 \mathrm{~cm}^{-1}$, which correspond to the well-known D and $\mathrm{G}$ bands, respectively. The $\mathrm{D}$ band is ascribed to the breathing mode of $\mathrm{A}_{1 \mathrm{~g}}$ symmetry, involving phonons near the $\mathrm{K}$ zone boundary. Meanwhile, the $\mathrm{G}$ band is assigned to the $\mathrm{E}_{2 \mathrm{~g}}$ mode of $\mathrm{sp}^{2}$-bonded carbon atoms. ${ }^{47}$ The $\mathrm{D}$ and $\mathrm{G}$ band positions and intensity ratios of $I(\mathrm{D}) / I(\mathrm{G})$ for the GO and AgNPs-rGO composites, prepared at different ultrasound irradiation times, are summarized in Table 1. In comparison to the pristine GO, the Raman spectra of the AgNPs-rGO composites show that the G band shifted to lower wavenumbers, which can be attributed to the reduction in GO during the ultrasonic irradiation process. ${ }^{\mathbf{4 8 , 4 9}}$ In addition, the intensity ratio of $I(\mathrm{D}) / I(\mathrm{G})$ for an AgNPs-rGO composite decreases with an increase in the ultrasonic irradiation time to 15 min compared to that of GO, which can be attributed to the formation of $\mathrm{sp}^{2}$ bonds during the ultrasonic irradiation process. ${ }^{50}$ However, when the ultrasonic irradiation time was further increased to $30 \mathrm{~min}$, the intensity ratio of $I(\mathrm{D}) / I(\mathrm{G})$ increased to a slightly higher value of 0.95 , compared to that of GO (0.91), which can be assigned to the formation of further defects in the rGO sheets. A possible explanation is that the prolonged reaction time is conducive to the increased formation of AgNPs on the rGO, thus overriding the $\mathrm{sp}^{2}$ hybridized carbon. Moreover, the intensity peaks of the $\mathrm{D}$ and $\mathrm{G}$ bands were enhanced in the case of AgNPS-rGO as a result of the SERS effect of the AgNPs. It is well-known that electromagnetic and
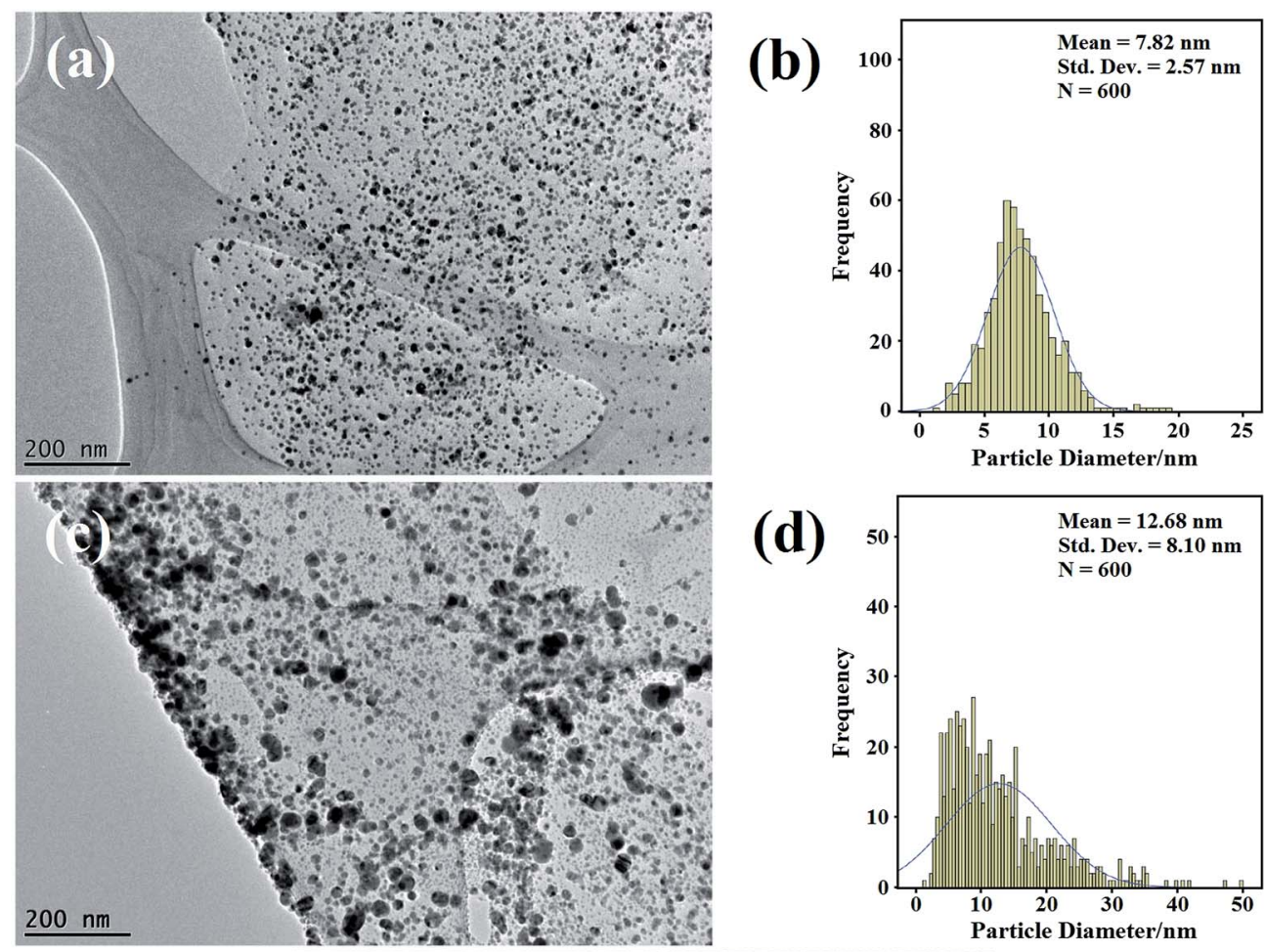

(d)
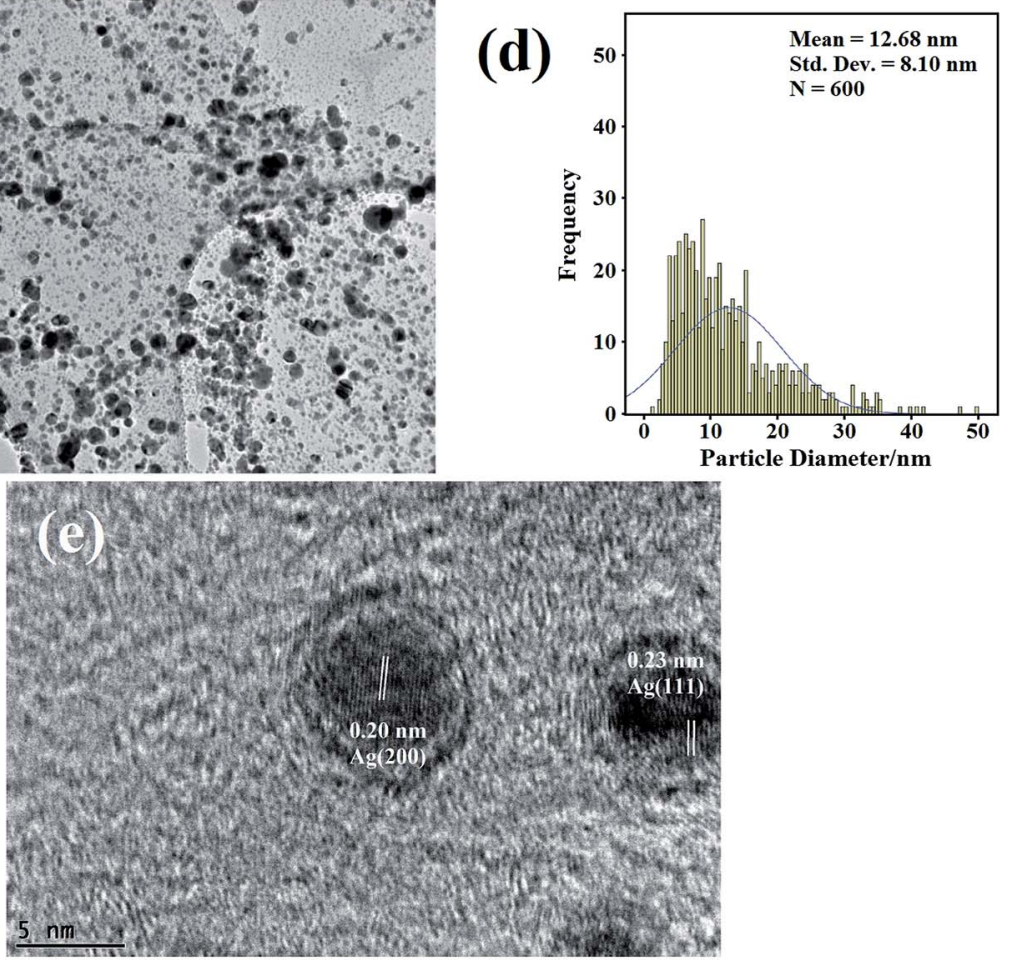

Fig. 7 TEM images and size distribution diagrams of AgNPs-rGO prepared by using solution with $\mathrm{GO}\left(1.0 \mathrm{mg} \mathrm{mL}^{-1}\right)$ to $\mathrm{Ag}\left(\mathrm{NH}_{3}\right)_{2} \mathrm{OH}(0.04 \mathrm{M})$ volume ratio of 4 at different ultrasonic irradiation times of $15 \mathrm{~min}$ ( $\mathrm{a}$ and $\mathrm{b}$ ) and $30 \mathrm{~min}$ ( $\mathrm{c}$ and d), and HRTEM image of AgNPs anchored on surface of graphene sheet (e). 
chemical enhancements are the origins of the SERS effect. Electromagnetic enhancement can be associated with the excitation of localized surface plasmon resonances (LSPR) of noble metal nanoparticles (such as $\mathrm{Ag}$ and $\mathrm{Au}$ ), with a large enhancement factor (up to $10^{12}$ ), whereas chemical enhancement can be attributed to the formation of charge-transfer complexes through chemical interaction, with a minor enhancement factor (up to 100). ${ }^{51,52}$ As shown in Fig. 5, the intensity peaks of the D and $G$ bands for the AgNPs-rGO composite increased from 1.3 to 4 times compared to that of GO with the increase in the ultrasonic irradiation time, which indicates the increase in AgNPs on the surface of the graphene nanosheets as the ultrasonic irradiation time increased. ${ }^{\mathbf{5 2}}$

Fig. 6 shows the typical TEM images and size distribution histograms of the AgNPs-rGO prepared by using solutions with $\mathrm{GO}\left(1.0 \mathrm{mg} \mathrm{mL}^{-1}\right)$ to $\mathrm{Ag}\left(\mathrm{NH}_{3}\right)_{2} \mathrm{OH}(0.04 \mathrm{M})$ volume ratios of 8 (a and b), 4 (c and d) and 2 (e and f), as well as a solution with a GO $\left(1.0 \mathrm{mg} \mathrm{mL}{ }^{-1}\right)$ to $\mathrm{AgNO}_{3}(0.04 \mathrm{M})$ volume ratio of $4(\mathrm{~g}$ and $\mathrm{h})$ at an ultrasonic irradiation time of $5 \mathrm{~min}$. As shown in Fig. 6(a) and (b), ultrafine spherical AgNPs with a mean size of $4.56 \mathrm{~nm}$ and a narrow size distribution are anchored and well distributed on the surface of the rGO sheets. Fig. 6(c)-(f) shows that the increased amount of $\mathrm{Ag}\left(\mathrm{NH}_{3}\right)_{2} \mathrm{OH}$ is commensurate with the mean size and size distribution. The type of Ag precursor appears to affect the size and coverage density of the nanoparticles on the surface of the graphene. When $\mathrm{AgNO}_{3}$ was used as a precursor of $\mathrm{Ag}$, the mean particle size increased to $9.96 \mathrm{~nm}$, and the size distribution widened, as shown in Fig. $6(\mathrm{~g})$ and (h). Moreover, the density of the particles was reduced tremendously compared to those prepared by using $\mathrm{Ag}\left(\mathrm{NH}_{3}\right)_{2} \mathrm{OH}$ as the precursor of $\mathrm{Ag}$, as a result of the clumping of nanoparticles. This implies that the ammonia molecules acted somewhat as a template for the nucleation and growth of AgNPs at a constraint geometry. The ammonia molecules critically controlled the particle size and size distribution of the AgNPs.

Fig. 7 shows typical TEM images and size distribution diagrams of the AgNPs-rGO prepared by using the solution with the $\mathrm{GO}\left(1.0 \mathrm{mg} \mathrm{mL}^{-1}\right)$ to $\mathrm{Ag}\left(\mathrm{NH}_{3}\right)_{2} \mathrm{OH}(0.04 \mathrm{M})$ volume ratio of 4 at different ultrasonic irradiation times of $15 \mathrm{~min}(\mathrm{a}$ and $\mathrm{b})$ and $30 \mathrm{~min}$ (c and d). As shown in Fig. 7, as the ultrasonic irradiation time increases from $5 \mathrm{~min}$ to 15 and $30 \mathrm{~min}$, the mean size increases from $5.67 \mathrm{~nm}$ to 7.82 and $12.68 \mathrm{~nm}$, respectively, and the size distribution broadens. Fig. 7(e) shows an HRTEM image of AgNPs anchored on the surface of the rGO sheet. The measured lattice fringe spaces of 0.23 and $0.20 \mathrm{~nm}$ are attributed to the (111) and (200) planes of silver crystal, respectively. In retrospect, the planes identified by TEM agree with those deduced from XRD.

The formation mechanism of the AgNPs-rGO via a sonochemical reaction is shown in Fig. 8. Dispersed GO sheets in water are negatively charged as a result of the ionization of the carboxyl and hydroxyl groups on the surface of the GO (Fig. 8(a)). ${ }^{53}$ This causes the positively charged $\left[\mathrm{Ag}\left(\mathrm{NH}_{3}\right)_{2}\right]^{+}$ions to be adsorbed on the negatively charged GO sheets by electrostatic attraction (Fig. 8(b)). When an aqueous solution is irradiated with ultrasound, bubbles are created and accumulate

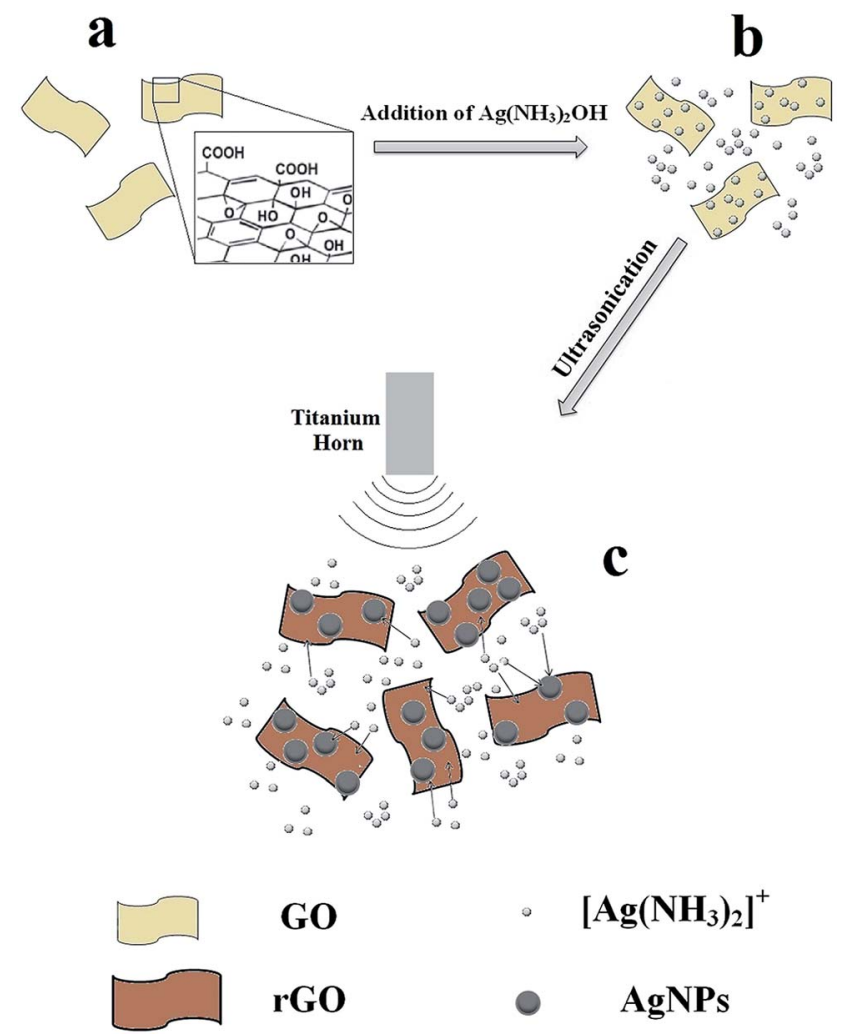

Fig. 8 Schematic illustration of formation mechanism for AgNPs-rGO composite via ultrasonic irradiation.

ultrasonic energy while growing. Rapid collapse of the bubbles leads to the creation of localized hotspots with a high temperature of $5000 \mathrm{~K}$, pressure of 1000 bar and heating and cooling rate of $10^{10} \mathrm{~K} \mathrm{~s}^{-1}$. Under these conditions, highly reactive $\mathrm{H}$ and $\mathrm{OH}$ radicals can be generated by the pyrolysis of water molecules. ${ }^{25}$

$$
\left.\left.\left.\left.\mathrm{H}_{2} \mathrm{O}()\right)\right)\right)\right) \mathrm{H}^{\bullet}+\mathrm{OH}^{\bullet}
$$

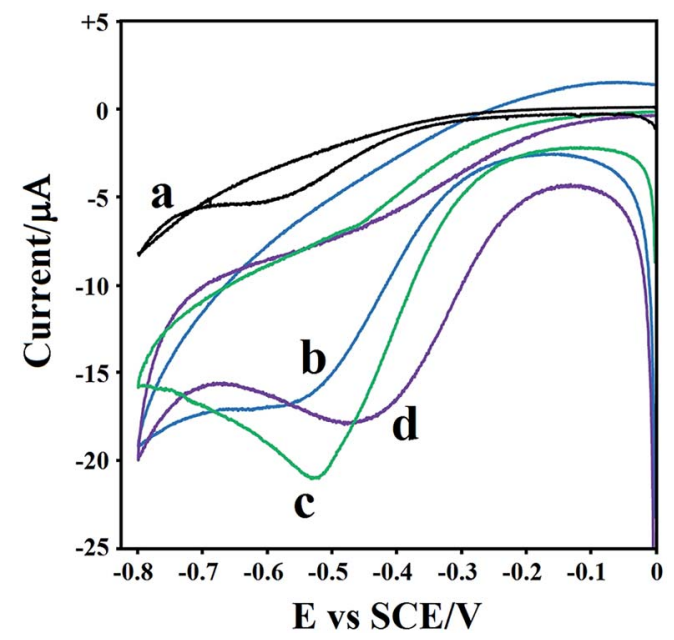

Fig. $9 \mathrm{CV}$ values of various electrodes in $0.2 \mathrm{M} \mathrm{PBS}(\mathrm{pH}$ 6.5) in presence of $1.0 \mathrm{mM} \mathrm{H}_{2} \mathrm{O}_{2}$ : (a) bare GCE and AgNPs-rGO/GCE prepared by using different ultrasonication times of (b) $5 \mathrm{~min}$, (c) $15 \mathrm{~min}$ and (d) $30 \mathrm{~min}$. 


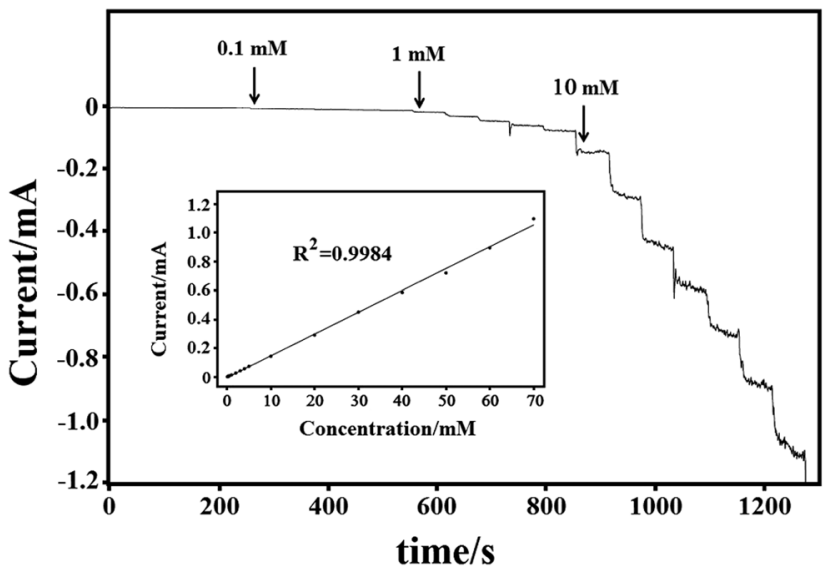

Fig. 10 Steady-state response of AgNPs-rGO-4/GCE to successive injections of $\mathrm{H}_{2} \mathrm{O}_{2}$ into stirred 0.2 M PBS ( $\mathrm{pH}$ 6.5) with applied potential of $-0.4 \mathrm{~V}$. The inset is the corresponding calibration curve.

The generated $\mathrm{H}^{*}$ radicals act as reducing species, resulting in reduction mechanisms: $:^{25,31}$

$$
\mathrm{Ag}^{+}+\mathrm{H}^{\cdot} \rightarrow \mathrm{Ag}^{0}+\mathrm{H}^{+}
$$

or

$$
2\left[\mathrm{Ag}\left(\mathrm{NH}_{3}\right)_{2}\right]^{+}+\mathrm{H}^{\cdot} \rightarrow 2 \mathrm{Ag}^{0}+\left(\mathrm{NH}_{4}\right)^{+}+\mathrm{NH}_{3}
$$

and

$$
\mathrm{GO}+\text { reducing species of } \mathrm{H}^{\cdot} \rightarrow \mathrm{rGO}
$$

The GO and adsorbed $\left[\mathrm{Ag}\left(\mathrm{NH}_{3}\right)_{2}\right]^{+}$or $\mathrm{Ag}^{+}$ions are simultaneously reduced to graphene and AgNPs by the ultrasonic irradiation process (Fig. 8(c)). In addition, GO is a thermally unstable material above $200{ }^{\circ} \mathrm{C}$. Hence, the high temperature generated during ultrasonic irradiation could reduce GO to graphene. ${ }^{13,54}$ When the concentration of the $\left[\mathrm{Ag}\left(\mathrm{NH}_{3}\right)_{2}\right]^{+}$ions or the ultrasonic irradiation time increased, the free $\left[\mathrm{Ag}\left(\mathrm{NH}_{3}\right)_{2}\right]^{+}$or $\mathrm{Ag}^{+}$ions in the aqueous solution continued to grow on the previously formed AgNPs, as well as nucleating on the rGO sheets, which explained the increased particle size and density on the rGO sheets. As can be seen in Fig. 6, the sonochemical reaction can be enhanced by using the silver ammonia complex instead of silver nitrate. The two plausible reasons are given as follows: (1) the negatively charged GO is enhanced through neutralization by the alkaline $\mathrm{Ag}\left(\mathrm{NH}_{3}\right)_{2} \mathrm{OH}$ to attract more $\left[\mathrm{Ag}\left(\mathrm{NH}_{3}\right)_{2}\right]^{+}$ions than $\mathrm{AgNO}_{3}$, leading to the creation of more initial nucleation sites; ${ }^{17}$ and (2) the ammonia can scavenge the $\mathrm{OH}$ radicals that are produced from pyrolysis to provide a reducing condition. ${ }^{55}$

AgNPs are typically known to exhibit high catalytic activity for the reduction of hydrogen peroxide. To investigate the effect of the ultrasonication time on the electrocatalytic activity of the AgNPs-rGO towards hydrogen peroxide reduction, cyclic voltammetry (CV) measurements of the AgNPs-rGO/GCE electrodes prepared at different ultrasonication times were conducted in a $0.2 \mathrm{M}$ phosphate buffer solution (PBS) at pH 6.5 in the presence of $1 \mathrm{mM} \mathrm{H}_{2} \mathrm{O}_{2}$. As shown in Fig. 9, all the AgNPsrGO/GCE electrodes exhibited a notable cathodic peak for the reduction of $\mathrm{H}_{2} \mathrm{O}_{2}$ in comparison to the bare GCE. As can be seen in Fig. 9, the catalytic activity of the AgNPs-rGO/GCE electrode was enhanced by an increase in the ultrasonication time used to prepare the composite from $5 \mathrm{~min}$ to $15 \mathrm{~min}$. A plausible reason is that a higher-density of AgNPs could be achieved on the surface of rGO by increasing the ultrasonication time, which enhanced the electrocatalytic activity of the composite. In addition, a further increase in the ultrasonication time to $30 \mathrm{~min}$ decreased the electrocatalytic activity of the composite towards the reduction of $\mathrm{H}_{2} \mathrm{O}_{2}$. A plausible reason is that, although a higher density of AgNPs could be achieved on the surface of the rGO, it consisted of larger AgNPs. These results are consistent with those of a previous study ${ }^{56}$ which implied that the electrocatalytic activity of silver nanoparticles decreased with increasing particle size and increased with increasing particle density. The reduction peak of all the AgNPs-rGO/GCE electrodes shifted to a positive potential as the size and density of the AgNPs increased. ${ }^{33,57}$

Fig. 10 shows the amperometric current-time response of

\begin{tabular}{|c|c|c|c|}
\hline Type of electrode & Limit of detection $(\mu \mathrm{M})$ & Linear range $(\mathrm{mM})$ & References \\
\hline Ag NPs-MWCNT/Au electrode & 0.5 & $0.05-17$ & 58 \\
\hline Ag NPs-GN-R/GCE & 28 & $0.1-40$ & 22 \\
\hline AgNP-PMPD/GCE & 4.7 & $0.1-30$ & 59 \\
\hline $\mathrm{MnO}_{2} \mathrm{NWs}-\mathrm{Ag} / \mathrm{GCE}$ & 0.24 & $0.1-4$ & 60 \\
\hline AgNP/GO/ssDNA/AuE & 1.9 & $0.1-20$ & 61 \\
\hline GN-AgNWs/GCE & 9.3 & $0.02-5.34$ & 32 \\
\hline Ag NPs-NFs/GCE & 62 & $0.1-80$ & 62 \\
\hline AgNPs-rGO/ITO & 5 & $0.1-100$ & 16 \\
\hline AgNP/rGO-benzylamine/GCE & 31.3 & $0.1-100$ & 15 \\
\hline PDDA-rGO/AgNPs/GCE & 35 & $0.1-41$ & 23 \\
\hline Ag NPs/3DG & 14.9 & $0.03-16.21$ & 63 \\
\hline AgNPs/rGO/GCE & 4.3 & $0.1-70$ & This work \\
\hline
\end{tabular}
the AgNPs-rGO- $4 / \mathrm{GCE}$ electrode at $-0.4 \mathrm{~V}$ in an $\mathrm{N}_{2}$-saturated

Table 2 Comparison of results from this work and literature regarding performance of $\mathrm{H}_{2} \mathrm{O}_{2}$ assays 
0.2 M PBS buffer (pH: 6.5) upon successive step changes in the $\mathrm{H}_{2} \mathrm{O}_{2}$ concentration. When an aliquot of $\mathrm{H}_{2} \mathrm{O}_{2}$ was injected in the stirring PBS solution, the reduction current rapidly changed to reach a steady-state value within $3 \mathrm{~s}$, indicating a fast amperometric response behaviour. The inset shows the corresponding calibration curve of the AgNPs-rGO-4/GCE electrode. The current response of the AgNPs-rGO-4/GCE electrode is estimated to be linear within the $\mathrm{H}_{2} \mathrm{O}_{2}$ concentration range of 0.1 to $70 \mathrm{mM}\left(R^{2}=0.9984\right)$, whereas the limit of detection is estimated to be $4.3 \mu \mathrm{M}$, based on a signal-to-noise ratio of three. The relative standard deviation (RSD) of the current response to $5 \mathrm{mM} \mathrm{H}_{2} \mathrm{O}_{2}$ at $-0.4 \mathrm{~V}$ is $5.6 \%$ for five successive measurements. Based on the results of a comparative analysis of different types of electrodes listed in Table 2, the present AgNPs-rGO/GCE electrode is demonstrated to be capable of affording a favourable detection limit and linear range for sensing $\mathrm{H}_{2} \mathrm{O}_{2}$.

In order to evaluate the sensitivity and application of the AgNPs-rGO composite to the determination of $\mathrm{Hg}^{2+}$ ions, the UV-vis absorbance peak related to the surface plasmon resonance (SPR) of silver nanoparticles was monitored during the addition of different concentrations of an aqueous solution of $\mathrm{Hg}^{2+}$ ions at room temperature. As shown in the inset of Fig. 11a, the colour of AgNPs/rGO gradually changes from brown-yellow to colourless with the increase in the $\mathrm{Hg}^{2+}$ ion concentrations. Fig. 11a shows the UV-vis absorbance values for the AgNPs-rGO composite in the absence and presence of different concentrations of $\mathrm{Hg}^{2+}$ ions, where the intensity of the absorbance peak decreases with an increasing concentration of $\mathrm{Hg}^{2+}$ ions. Accompanied by the extinction intensity of the peak, the SPR peak position shifts toward shorter wavelengths. This phenomenon can be explained by the redox reaction between the $\mathrm{Hg}^{2+}$ ions and $\mathrm{Ag}$ atoms. Because the redox potential of the $\mathrm{Hg}^{2+} / \mathrm{Hg}^{0}(0.85 \mathrm{~V})$ is higher than that of the $\mathrm{Ag}^{+} / \mathrm{Ag}^{0}(0.8 \mathrm{~V}), \mathrm{Hg}^{2+}$ ions oxidize the metallic $\mathrm{Ag}$ atoms, which produces metallic $\mathrm{Hg}$ atoms and $\mathrm{Ag}^{+}$ions. According to the previous reports, the blue shift in the SPR peak can be related to the adsorption of $\mathrm{Hg}$ onto Ag NPs. ${ }^{64,65}$ Fig. 11b shows a calibration curve related to the difference in the absorbance peak of the AgNPs-rGO composite, which is subject to the concentration of $\mathrm{Hg}^{2+}$ ions. The intensity of the absorbance peak rapidly decreases with an increase in the concentration of $\mathrm{Hg}^{2+}$ ions up to $10 \mu \mathrm{M}$. Above this concentration, the intensity of the absorbance peak slowly decreases with good linearity. A plausible reason for the two linear ranges is that with the increase in the $\mathrm{Hg}^{2+}$ ion concentration above 10 $\mu \mathrm{M}$, the formation of a metallic $\mathrm{Hg}$ layer around the $\mathrm{Ag}$ nanoparticles may occur, which decreases the sensitivity and produces the second linear range. ${ }^{65}$ The estimated limit of detection is $20 \mathrm{nM}$, based on a signal-to-noise ratio of three. Further experiments were carried out to investigate the selective sensing of $\mathrm{Hg}^{2+}$ ions by AgNPs-rGO in the presence of other environmentally relevant metal ions $\left(\mathrm{Fe}^{2+}, \mathrm{K}^{+}, \mathrm{Mn}^{2+}, \mathrm{Pb}^{2+}, \mathrm{Zn}^{2+}\right.$, $\mathrm{Cd}^{2+}, \mathrm{Cu}^{2+}$ and $\mathrm{Ni}^{2+}$ ). As shown in Fig. 11c, the SPR peak of AgNPs/rGO was dramatically quenched only by the addition of $\mathrm{Hg}^{2+}$, and no significant changes in the SPR peak were observed by the addition of other metal ions, which demonstrated the selective sensing ability of the prepared AgNPs/rGO composite toward $\mathrm{Hg}^{2+}$ ions.
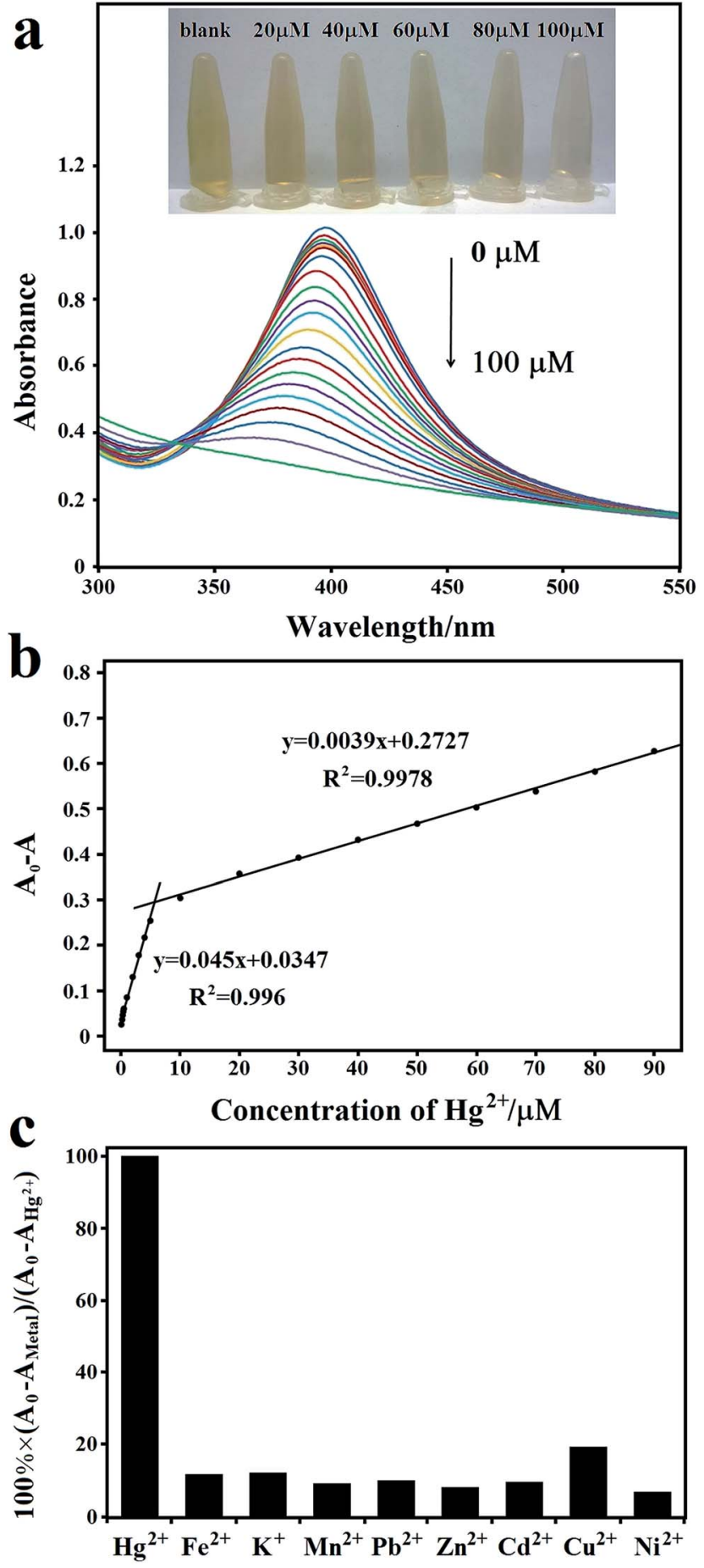

Fig. 11 (a) Absorbance responses of AgNPs-rGO composite for different concentrations of $\mathrm{Hg}^{2+}$ ions from 0.1 to $100 \mu \mathrm{M}$. The inset shows the gradual colour change of the AgNPs-rGO solution with the increase in the $\mathrm{Hg}^{2+}$ ion concentration. (b) The corresponding calibration curve for the $\mathrm{Hg}^{2+}$ ion detection. (c) The relative absorbance change in AgNPs-rGO in the presence of $\mathrm{Hg}^{2+}$ ions and some other common metal ions. 


\section{Conclusion}

The ultrasonic irradiation of an aqueous solution containing a silver ammonia complex $\left(\mathrm{Ag} \cdot\left(\mathrm{NH}_{3}\right)_{2} \mathrm{OH}\right)$ and graphene oxide (GO) is a simple strategy for producing rGO uniformly decorated with ultrafine AgNPs with a narrow size distribution. It was established that the silver ammonia complex is the key to the successful synthesis of well-formed composites. The particle size of the AgNPs embedded on the rGO sheets could be easily tuned by adjusting the ultrasonic radiation time or the amount of $\mathrm{Ag}\left(\mathrm{NH}_{3}\right)_{2} \mathrm{OH}$. The prepared AgNPs-rGO composite exhibited a promising potential application to the enzyme-less electrochemical detection of hydrogen peroxide and the SPR optical sensing of mercury ions.

\section{Acknowledgements}

This work was supported by the UMRG Program Grant (RP007C/ 13AFR) by University of Malaya and a High Impact Research Grant from the Ministry of Higher Education of Malaysia (UM.C/625/1/HIR/MOHE/SC/21).

\section{References}

1 K. S. Novoselov, A. K. Geim, S. V. Morozov, D. Jiang, Y. Zhang, S. V. Dubonos, I. V. Grigorieva and A. A. Firsov, Science, 2004, 306, 666-669.

2 C. Lee, X. Wei, J. W. Kysar and J. Hone, Science, 2008, 321, 385-388.

3 A. A. Balandin, S. Ghosh, W. Bao, I. Calizo, D. Teweldebrhan, F. Miao and C. N. Lau, Nano Lett., 2008, 8, 902-907.

4 S. Gilje, S. Han, M. Wang, K. L. Wang and R. B. Kaner, Nano Lett., 2007, 7, 3394-3398.

5 M. Zhou, Y. Zhai and S. Dong, Anal. Chem., 2009, 81, 56035613.

6 C. Liu, Z. Yu, D. Neff, A. Zhamu and B. Z. Jang, Nano Lett., 2010, 10, 4863-4868.

7 X. Huang, X. Qi, F. Boey and H. Zhang, Chem. Soc. Rev., 2012, 41, 666-686.

8 A. Guermoune, T. Chari, F. Popescu, S. S. Sabri, J. Guillemette, H. S. Skulason, T. Szkopek and M. Siaj, Carbon, 2011, 49, 4204-4210.

9 H.-L. Guo, X.-F. Wang, Q.-Y. Qian, F.-B. Wang and X.-H. Xia, ACS Nano, 2009, 3, 2653-2659.

10 C. Berger, Z. Song, X. Li, X. Wu, N. Brown, C. Naud, D. Mayou, T. Li, J. Hass, A. N. Marchenkov, E. H. Conrad, P. N. First and W. A. de Heer, Science, 2006, 312, 1191-1196.

11 H. C. Schniepp, J.-L. Li, M. J. McAllister, H. Sai, M. HerreraAlonso, D. H. Adamson, R. K. Prud'homme, R. Car, D. A. Saville and I. A. Aksay, J. Phys. Chem. B, 2006, 110, 8535-8539.

12 S. Stankovich, D. A. Dikin, R. D. Piner, K. A. Kohlhaas, A. Kleinhammes, Y. Jia, Y. Wu, S. T. Nguyen and R. S. Ruoff, Carbon, 2007, 45, 1558-1565.

13 K. Krishnamoorthy, G.-S. Kim and S. J. Kim, Ultrason. Sonochem., 2013, 20, 644-649.
14 Y. Zhang, S. Liu, L. Wang, X. Qin, J. Tian, W. Lu, G. Chang and X. Sun, RSC Adv., 2012, 2, 538-545.

15 S. Liu, J. Tian, L. Wang and X. Sun, Carbon, 2011, 49, 31583164.

16 A. Moradi Golsheikh, N. M. Huang, H. N. Lim, R. Zakaria and C.-Y. Yin, Carbon, 2013, 62, 405-412.

17 Y. Zhang, X. Yuan, Y. Wang and Y. Chen, J. Mater. Chem., 2012, 22, 7245-7251.

18 J. Li and C.-y. Liu, Eur. J. Inorg. Chem., 2010, 2010, 12441248.

19 J. Ma, J. Zhang, Z. Xiong, Y. Yong and X. S. Zhao, J. Mater. Chem., 2011, 21, 3350-3352.

20 J. Liu, S. Fu, B. Yuan, Y. Li and Z. Deng, J. Am. Chem. Soc., 2010, 132, 7279-7281.

21 B. Yu, J. Feng, S. Liu and T. Zhang, RSC Adv., 2013, 3, 1430314307.

22 S. Liu, J. Tian, L. Wang, H. Li, Y. Zhang and X. Sun, Macromolecules, 2010, 43, 10078-10083.

23 X. Liu, X. Xu, H. Zhu and X. Yang, Anal. Methods, 2013, 5, 2298-2304.

24 S. K. Tripathy, A. Mishra, S. K. Jha, R. Wahab and A. A. AlKhedhairy, Anal. Methods, 2013, 5, 1456-1462.

25 V. G. Pol, D. N. Srivastava, O. Palchik, V. Palchik, M. A. Slifkin, A. M. Weiss and A. Gedanken, Langmuir, 2002, 18, 3352-3357.

26 M. Darroudi, A. Khorsand Zak, M. R. Muhamad, N. M. Huang and M. Hakimi, Mater. Lett., 2012, 66, 117-120.

27 A. Khorsand Zak, W. H. a. Majid, H. Z. Wang, R. Yousefi, A. Moradi Golsheikh and Z. F. Ren, Ultrason. Sonochem., 2013, 20, 395-400.

28 J. Geng, X.-D. Jia and J.-J. Zhu, CrystEngComm, 2011, 13, 193198.

29 Y. Wu, X. Hao, J. Yang, F. Tian and M. Jiang, Mater. Lett., 2006, 60, 2764-2766.

30 J. H. Bang and K. S. Suslick, Adv. Mater., 2010, 22, 1039-1059.

31 K. Vinodgopal, B. Neppolian, I. V. Lightcap, F. Grieser, M. Ashokkumar and P. V. Kamat, J. Phys. Chem. Lett., 2010, 1, 1987-1993.

32 S. Chandra, S. Bag, R. Bhar and P. Pramanik, J. Nanopart. Res., 2011, 13, 2769-2777.

33 S. Anandan, A. Manivel and M. Ashokkumar, Fuel Cells, 2012, 12, 956-962.

34 Q.-P. Luo, X.-Y. Yu, B.-X. Lei, H.-Y. Chen, D.-B. Kuang and C.-Y. Su, J. Phys. Chem. C, 2012, 116, 8111-8117.

35 G. Park, L. Bartolome, K. G. Lee, S. J. Lee, D. H. Kim and T. J. Park, Nanoscale, 2012, 4, 3879-3885.

36 S. Zhu, J. Guo, J. Dong, Z. Cui, T. Lu, C. Zhu, D. Zhang and J. Ma, Ultrason. Sonochem., 2013, 20, 872-880.

37 N. M. Huang, H. N. Lim, C. H. Chia, M. A. Yarmo and M. R. Muhamad, Int. J. Nanomed., 2011, 6, 3443-3448.

38 G. Xie, J. Cheng, Y. Li, P. Xi, F. Chen, H. Liu, F. Hou, Y. Shi, L. Huang, Z. Xu, D. Bai and Z. Zeng, J. Mater. Chem., 2012, 22, 9308-9314.

39 M. A. Tagliente and M. Massaro, Nucl. Instrum. Methods Phys. Res., Sect. B, 2008, 266, 1055-1061.

40 J. I. Paredes, S. Villar-Rodil, A. Martínez-Alonso and J. M. D. Tascón, Langmuir, 2008, 24, 10560-10564. 
41 B. Su, D. Tang, Q. Li, J. Tang and G. Chen, Anal. Chim. Acta, 2011, 692, 116-124.

42 A. M. Abdel-Mohsen, R. Hrdina, L. Burgert, G. Krylová, R. M. Abdel-Rahman, A. Krejčová, M. Steinhart and L. Beně̌, Carbohydr. Polym., 2012, 89, 411-422.

43 C. Cheng, S. Nie, S. Li, H. Peng, H. Yang, L. Ma, S. Sun and C. Zhao, J. Mater. Chem. B, 2013, 1, 265-275.

44 V. H. Pham, T. V. Cuong, S. H. Hur, E. Oh, E. J. Kim, E. W. Shin and J. S. Chung, J. Mater. Chem., 2011, 21, 3371-3377.

45 D. R. Dreyer, S. Park, C. W. Bielawski and R. S. Ruoff, Chem. Soc. Rev., 2010, 39, 228-240.

46 S. Pei, J. Zhao, J. Du, W. Ren and H.-M. Cheng, Carbon, 2010, 48, 4466-4474.

47 A. C. Ferrari and J. Robertson, Phys. Rev. B: Condens. Matter Mater. Phys., 2000, 61, 14095-14107.

48 T. N. Lambert, C. A. Chavez, B. Hernandez-Sanchez, P. Lu, N. S. Bell, A. Ambrosini, T. Friedman, T. J. Boyle, D. R. Wheeler and D. L. Huber, J. Phys. Chem. C, 2009, 113, 19812-19823.

49 A. M. Golsheikh, N. M. Huang, H. N. Lim, C. H. Chia, I. Harrison and M. R. Muhamad, Chem. Eng. J., 2013, 218, 276-284.

50 M. Shi, J. Shen, H. Ma, Z. Li, X. Lu, N. Li and M. Ye, Colloids Surf., A, 2012, 405, 30-37.

51 G. Baker and D. Moore, Anal. Bioanal. Chem., 2005, 382, 1751-1770.

52 Z. Xu, H. Gao and H. Guoxin, Carbon, 2011, 49, 4731-4738.
53 D. Li, M. B. Muller, S. Gilje, R. B. Kaner and G. G. Wallace, Nat. Nanotechnol., 2008, 3, 101-105.

54 K. Krishnamoorthy, M. Veerapandian, R. Mohan and S.-J. Kim, Appl. Phys. A: Mater. Sci. Process., 2012, 106, 501506.

55 L. Huang, L. Li, W. Dong, Y. Liu and H. Hou, Environ. Sci. Technol., 2008, 42, 8070-8075.

56 A. Yu, Q. Wang, J. Yong, P. J. Mahon, F. Malherbe, F. Wang, H. Zhang and J. Wang, Electrochim. Acta, 2012, 74, 111-116.

57 F. W. Campbell, S. R. Belding, R. Baron, L. Xiao and R. G. Compton, J. Phys. Chem. C, 2009, 113, 9053-9062.

58 W. Zhao, H. Wang, X. Qin, X. Wang, Z. Zhao, Z. Miao, L. Chen, M. Shan, Y. Fang and Q. Chen, Talanta, 2009, 80, 1029-1033.

59 J. Tian, H. Li, W. Lu, Y. Luo, L. Wang and X. Sun, Analyst, 2011, 136, 1806-1809.

60 Q. Han, P. Ni, Z. Liu, X. Dong, Y. Wang, Z. Li and Z. Liu, Electrochem. Commun., 2014, 38, 110-113.

61 W. Lu, G. Chang, Y. Luo, F. Liao and X. Sun, J. Mater. Sci., 2011, 46, 5260-5266.

62 J. Tian, S. Liu and X. Sun, Langmuir, 2010, 26, 15112-15116. 63 B. Zhan, C. Liu, H. Shi, C. Li, L. Wang, W. Huang and X. Dong, Appl. Phys. Lett., 2014, 104, 243704.

64 A. Henglein and C. Brancewicz, Chem. Mater., 1997, 9, 21642167.

65 T. Morris, H. Copeland, E. McLinden, S. Wilson and G. Szulczewski, Langmuir, 2002, 18, 7261-7264. 